\title{
Research Square \\ Biomechanical Study of Cortical Bone Trajectory Screws in Intervertebral Fixation of Lumbar Tuberculosis
}

\section{Chen-Wei Zhang}

Hangzhou Red Cross Hospital https://orcid.org/0000-0001-8016-5371

\section{Shi-Yuan Shi}

Hangzhou Red Cross Hospital

De-Xin Hu

Hangzhou Red Cross Hospital

\section{Shen-Ping Hu}

Hangzhou Red Cross Hospital

Jin-Ping Hu

Hangzhou Red Cross Hospital

\section{Peng Zhang}

Hangzhou Red Cross Hospital

\section{Rui Xu}

Hangzhou Red Cross Hospital

Jun Fei ( $\square$ jamfee67@163.com )

Hangzhou Red Cross Hospital

\section{Research Article}

Keywords: Tuberculosis, spine, Internal fixator, Spinal fusion, Disease model, animal, Comparative study

Posted Date: July 8th, 2021

DOl: https://doi.org/10.21203/rs.3.rs-680733/v1

License: (1) (1) This work is licensed under a Creative Commons Attribution 4.0 International License. Read Full License 


\section{Abstract}

\section{Background}

We aimed to explore the biomechanical stability and advantages of cortical bone trajectory (CBT) screws in the treatment of lumbar spine tuberculosis and provide biomechanical basis for the choice of clinical fixation methods.

\section{Methods}

16 pig spine specimens (T12-L5) were selected to simulate the lumbar spine(L2-L3) tuberculosis bone destruction model in vitro. The 16 specimens were randomly divided into 4 groups, and short segments (pedicle screws of the diseased vertebrae) were assigned respectively. Fixation (group A), short-segment fixation (group B), fixation with pedicle screw (group C), fixation with CBT screw (group D), 4 specimens in each group, Each specimen in each group was subjected to biomechanical testing in the state of complete specimen (state 1) and L2-3 spinal tuberculosis model bone graft fusion and internal fixation (state 2). Load each specimen on the spine 3D exercise machine, respectively apply moments of $2 \mathrm{~N} \cdot \mathrm{m}$, $2.5 \mathrm{~N} \cdot \mathrm{m}, 1 \mathrm{~N} \cdot \mathrm{m}, 3 \mathrm{~N} \cdot \mathrm{m}$, meanwhile record the movement of the specimens in the four directions of flexion $\mathbb{}$ extension『lateral bending and torsion ROM, compare Simultaneously analyze each group of ROM.

Results

The ROMs of flexion, extension, lateral bending, and torsion in group A in state 1 and state 3 modes were

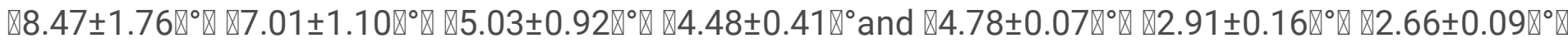
$\otimes 2.23 \pm 0.05 \bigotimes^{\circ}$; the ROMs of flexion, extension, lateral bending and torsion in group B in state 1 and state 3

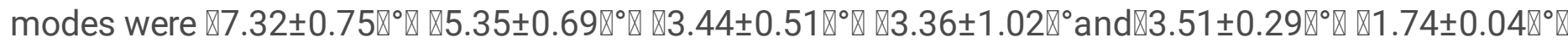
$\nabla 1.53 \pm 0.31 \otimes^{\circ} \otimes \nabla 1.23 \pm 0.08 \otimes^{\circ}$; The ROMs of flexion, extension, lateral bending, and torsion in group $\mathrm{C}$ in

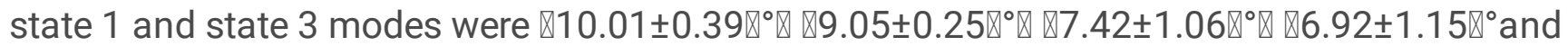

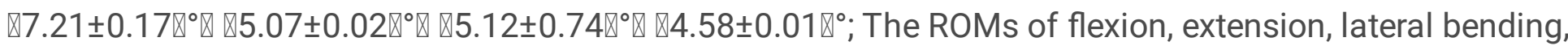
and torsion in group $D$ in state 1 and state 3 modes were $\nabla 9.20 \pm 1.37 \nabla^{\circ} \nabla \nabla 7.38 \pm 0.88 \nabla^{\circ} \nabla \nabla 6.89 \pm 1.22 \nabla^{\circ} \nabla$

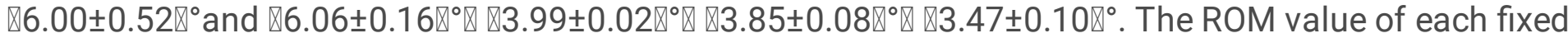
mode group under the state of bone graft fusion and internal fixation was lower than that of the intact state, and the difference was statistically significant $(P<0.05) \bigotimes$ The t values are 4.531, 5.346, 6.008, 4.149; $9.481,16.181,11.814,4.769 ; 4.349,8.002,4.473,4.800 ; 5.041,4.146,12.232,10.58$.

Conclusion

CBT screw disease intervertebral fixation can not only provide sufficient mechanical stability, but also provide stronger stability when using the same fixed segment, and The fixed segments are minimized.

\section{Introduction}


Spinal tuberculosis is the most common bone and joint tuberculosis, accounting for about $50 \%$ of bone and joint tuberculosis, of which lumbar tuberculosis has the highest incidence. With the increase of human immunodeficiency virus (HIV) infection rate and drug-resistant strains, the incidence of spinal tuberculosis is increasing year by year ${ }^{[1,2]}$. Due to the serious pathological process, spinal tuberculosis often causes anterior middle column injury, which results in the biomechanical stability and structural integrity destruction of the spine during the progression of the disease. These lesions further leading to spinal instability and neurovascular damage, and severe complications including kyphosis and paraplegia appear afterwards.. In recent years, the number of patients with spinal tuberculosis in Chinahas been on the rise. Anti-tuberculosis drug treatment is difficult to penetrate the sclerotic bone formed by the tuberculosis lesion, and cannot achieve effective antibacterial or bactericidal blood concentration around the lesion. Therefore, It is often difficult to achieve satisfactory results with only drug treatment. Under the premise of standardizing anti-tuberculosis treatment, timely surgical intervention is an indispensable means to improve curative effect and prognosis ${ }^{[3]}$. Current studies have shown that surgical treatment of spinal tuberculosis has achieved a certain effect. For example, high spinal tuberculosis such as single-segment or multi-segment tuberculosis of the lumbar spine can be operated to remove the lesion, decompress the spinal nerve, correct kyphotic deformity, and reconstruct spinal stability. Spinal tuberculosis often damages the anterior and middle column structure, and it is often difficult to make full use of the three-column fixation effect of traditional pedicle screws to provide reliable fixation. At the same time, traditional pedicle screw placement has certain requirements on the residual height of the vertebral body, which limits this internal fixation applications. Clinically, the proportion of elderly patients with spinal tuberculosis has increased significantly. Because Because the patient also suffers from osteoporosis, it is difficult for traditional pedicle screws to provide effective resistance to extraction and torsion. Therefore, the current clinical practice of spinal tuberculosis surgery mostly uses multi-segment fixation that fixes multiple motion units around the diseased vertebra. ${ }^{[4]}$. However冈long fixed segment will have a inevitable impact on the normal physiological structure and motor function of the spine. Increasing in the stress of the fixed adjacent segment often leads to a decrease mobility of the fusion site and degeneration of the adjacent segment. At the same time, more tissues need to be exposed during the operation, which could cause trauma, increase the operation time, and the amount of blood loss during the operation. Santoni et al ${ }^{[5]}$ proposed a new type of screw placement, the cortical bone trajectory (CBT) screw placement technology: the screw passes through the pedicle sagittal plane from the dorsal to the ventral side, and the axial position from the median to the lateral. The placement of the pedicle screw greatly increases the contact area of the screw in the intracortical bone channel on the 4 sides of the pedicle compared with the traditional pedicle screw, which is not limited by the residual volume of the anterior column of the vertebral body, and at the same time strengthens the holding force of the screw And stability, as far as possible to reduce the fixed segment and operation time. The use of CBT screw intervertebral fixation in the treatment of lumbar tuberculosis can provide stable fixation and reduce related complications. However, there are few biomechanical studies on intervertebral fixation and other internal fixation schemes for CBT screw disease. The author compares four kinds of posterior fixation methods of lumbar spine tuberculosis in biomechanical experiments, in order to provide a basis for the selection of clinical fixation modes. 


\section{Materials And Methods}

Preparation of experimental specimens

16 pig spine specimens were selected and screened by x-ray to exclude: deformities, vertebral body collapse, tumors and other serious bone structure diseases or abnormalities. All specimens were carefully removed the muscles around the vertebral body with surgical instruments . Keep the anterior and posterior longitudinal ligaments, ligamentum flavum, supraspinal and interspine ligaments. The uppermost and lowermost vertebral bodies $(T 12, L 5)$ of the specimen are poured with resin (Type II denture base resin produced by Shanghai Medical Instrument Co, Ltd. Dental Material Factory) platform. Use a level to measure the upper and lower ends to ensure that the upper and lower ends are parallel to facilitate Fixed on the material testing machine for measurement. All specimens were wrapped with wet water gauze for moisturizing during processing, and stored at $-20^{\circ} \mathrm{C}$ until the test started.

\section{Experimental Equipment}

The internal fixation system is the GSS-IV pedicle screw rod system produced by Jiangsu Chuangsheng Medical Instrument Co., Ltd., including 3 types of pedicle screws: $6.0 \mathrm{~mm} \times 40 \mathrm{~mm}$ (hereinafter referred to as "long nails"), $6.0 \mathrm{~mm} \times 25 \mathrm{~mm}$ (Hereinafter referred to as "short nails"), $4.5 \mathrm{~mm} \times 25 \mathrm{~mm}$ (hereinafter referred to as "CBT nails"); two types of fixed rods: $6.0 \mathrm{~mm} \times 170 \mathrm{~mm}$ (for short-segment fixation), $6.0 \mathrm{~mm}$ $\times 100 \mathrm{~mm}$ (for single-stage fixation). The implementation of all biomechanical tests uses a multi-degreeof-freedom spine motion simulation test system (MTS) test system (instrument model: MTS Bionix 370.02) provided by the Biomechanics Laboratory of Tianjin Medical University. Through the threedimensional motion measurement system (by Composed of gait/body analysis system, system control unit, data acquisition unit, etc.) measure and analyze the overall activity of each group in all directions.

\section{Grouping of Experimental Specimens}

The 16 specimens were divided into 4 groups by random number table method, with 4 specimens in each group. All specimens were first processed in a complete state (state 1) to measure the vertebral body motion. Subsequently, group A: fixed vertebral bodies were L1, L2, L3, L4, of which L1, L4 used long nails, L2, L3 used short nails, and bilateral nails (8 nails and two rods) were placed through traditional pedicle approach (Fig. 1-A); Group B: fixed vertebral bodies are L1, L2, L3, L4, of which L1, L4 are inserted through traditional approach with long screws, L2, L3 are inserted through CBT approach with CBT screws (8 screws and two rods) (Fig. 1-B); Group C: fixed vertebral bodies are L2 and L3, short nails (4 nails and two rods) are used to place the nails through the traditional pedicle approach, and the fixed segments are L2-L3 (Fig. 1-C) ; Group D: fixed vertebral bodies are L2 and L3, using CBT screws (4 screws and two rods) to place the screws through the CBT approach, and the fixed segments are L2-L3 (Fig. 1-D). According to the method of Gurr et al. ${ }^{[6]}$, surgical instruments such as osteotome, rongeur and nucleus pliers were used to remove the L2-L3 intervertebral disc, L2 lower endplate, and L3 upper endplate, each $2 \mathrm{~cm}$ in the range of the anterior middle column, resulting in L2 -L3 Severe anterior middle column injury vertebral tuberculosis model. And use the denture base resin to make bone graft material of appropriate 
size, simulate the operation to support the bone graft, simulate the L2-L3 spinal tuberculosis model bone graft fusion and internal fixation (state 2), and then measure the degree of movement on the machine (Fig. 2). During the test on the machine, spray the specimen with saline to keep it moist. The test of each specimen is completed within 1 day.

Sample loading and Sensor Fixation

The head and tail of all samples are wrapped around the base of the resin platform of the denture base. First, the distal end (L5) of the specimen is $1 \mathrm{~cm}$ away from the bottom of the fixing box and tightened with 4 fixing screws at the same time. Fix the specimen in the center of the bottom of the box and the sagittal plane of the specimen is perpendicular to the spine three-dimensional motion testing machine,Tighten the fixing screw when the specimen is $1 \mathrm{~cm}$ away from the top of the cap at the close (T12) . 8 three-dimensional motion measurement system recorders (Canada NDI company), marked as No. 1-8 in sequence, and fixed in order on both sides of the transverse process of the specimen L1-L4 vertebral body (Fig. 3)

Test method

Mechanical loading: All biomechanical tests are implemented in the MTS spine motion simulation test system, which is completed in a non-destructive manner. The specimens of different fixation groups (group A, B, C, D) and different fixation states (state 1,2) were subjected to normal physiological threedimensional movement of the lumbar spine with $2 \mathrm{n} \cdot \mathrm{m}$ pure torque for forward flexion , $2.5 \mathrm{n} \cdot \mathrm{m}$ pure torque for extension, $1 \mathrm{~N} \cdot \mathrm{m}$ pure torque for scoliosis, and $3 \mathrm{~N} \cdot \mathrm{m}$ pure torque for torsion respectively (Fig.4). The loading speed was $2 \mathrm{~mm} / \mathrm{min}$, and The set termination condition is that the specimen vibrates during the experimental torque loading process. Each on-machine test is carried out 3 cycles of torque loading and unloading, and data is collected in the third cycle to reduce the effects of tissue viscoelasticity and specimen relaxation and creep. During the test, operate carefully and gently to avoid specimen damage. During the test, normal saline was sprayed on the specimen every 10 minutes to keep it moist until the experiment was completed. The ambient temperature of the test is $25^{\circ} \mathrm{C}$, and the humidity is $60 \%$ to $80 \%$. The unmeasured specimens are sealed with cling film and stored at $-20^{\circ} \mathrm{C}$, and are naturally thawed at room temperature before testin

\section{Data collection}

A gait analysis system (NDI three-dimensional motion measurement system) measures the activity of the whole specimen and each segment. This experiment uses 1 positioning sensor, 3 sensing lenses, and 8 recorders to record the three-dimensional motion images of the spine when shooting at a fixed point with zero load and maximum load. A supporting software system is used to analyze the motion images and calculate the activity of the measured segment. For each on-machine test, three loading and unloading movements are carried out, with an interval of 1 min each, and the data shall be recorded based on the third test (thereby reducing the effects of specimen viscoelasticity, creep, etc., and obtaining stable and feasible data), Each group of specimens are sequentially measured for state 1 and state 2 state motions. 


\section{Statistical processing}

The data was analyzed by SPSS25.0 software, and the mean \pm standard deviation ( $x \pm s$ ) was used to describe the measurement data such as activity. Paired t-test was used for the sample activity of each group before and after the model was fixed; the comparison between group $A$ and group $B$, group $C$ and group $\mathrm{D}$ state 2 activity was compared by paired $\mathrm{t}$ test, and $\mathrm{P}<0.05$ was considered statistically significant.

\section{Results}

Comparison of the range of activity in each direction of movement between state 1 and state 2 in group $\mathrm{A}$

In group $A$, the range of activity in each direction of movement in state 2 was lower than that in state 1 , and the differences were statistically significant (all $P$-values $<0.05)($ Table 1$)$.

Table 1 Comparison of the range of movement of each specimen in group $A$ in each direction of movement in state 1 and state $2 \otimes^{\circ} \rrbracket{ }^{`} X \pm s \rrbracket$

\begin{tabular}{|lllll|}
\hline State & $\begin{array}{l}\text { Forward flexion } \\
\text { motion }\end{array}$ & $\begin{array}{l}\text { Extension } \\
\text { movement }\end{array}$ & $\begin{array}{l}\text { Scoliosis } \\
\text { movement }\end{array}$ & $\begin{array}{l}\text { Torsion } \\
\text { movement }\end{array}$ \\
\hline State 1 & $8.47 \pm 1.76$ & $7.01 \pm 1.10$ & $5.03 \pm 0.92$ & $4.48 \pm 0.41$ \\
\hline State 2 & $4.78 \pm 0.07$ & $2.91 \pm 0.16$ & $2.66 \pm 0.09$ & $2.23 \pm 0.05$ \\
\hline$t$-value & 4.531 & 5.346 & 6.008 & 4.149 \\
\hline$P$-value & 0.020 & 0.013 & 0.009 & 0.025 \\
\hline
\end{tabular}

Comparison of the range of activity in each direction of movement between state 1 and state 2 in group B

In group $B$, the range of activity in each direction of movement in state 2 was lower than that in state 1 , and the differences were statistically significant (all $P$-values $<0.05)($ Table 2$)$.

Table 2 Comparison of the range of movement of each specimen in group B in each direction of movement in state 1 and state $2 \otimes^{\circ} \rrbracket{ }^{\top} X \pm s \rrbracket$

\begin{tabular}{|lllll|}
\hline State & $\begin{array}{l}\text { Forward flexion } \\
\text { motion }\end{array}$ & $\begin{array}{l}\text { Extension } \\
\text { movement }\end{array}$ & $\begin{array}{l}\text { Scoliosis } \\
\text { movement }\end{array}$ & $\begin{array}{l}\text { Torsion } \\
\text { movement }\end{array}$ \\
\hline State 1 & $7.32 \pm 0.75$ & $5.35 \pm 0.69$ & $3.44 \pm 0.51$ & $3.36 \pm 1.02$ \\
\hline State 2 & $3.51 \pm 0.29$ & $1.74 \pm 0.04$ & $1.53 \pm 0.31$ & $1.23 \pm 0.08$ \\
\hline$t$-value & 9.481 & 16.181 & 11.814 & 4.769 \\
\hline$P$-value & 0.002 & 0.001 & 0.001 & 0.018 \\
\hline
\end{tabular}


Comparison of the range of activity in each direction of movement between state 1 and state 2 in group $\mathrm{C}$ In group $C$, the range of activity in each direction of movement in state 2 was lower than that in state 1 , and the differences were statistically significant (all $P$-values $<0.05)($ Table 3$)$.

Table 3 Comparison of the range of movement of each specimen in group $\mathrm{C}$ in each direction of

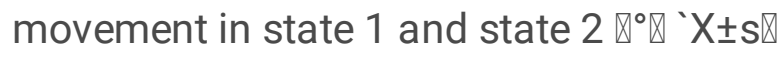

\begin{tabular}{|lllll|}
\hline State & $\begin{array}{l}\text { Forward flexion } \\
\text { motion }\end{array}$ & $\begin{array}{l}\text { Extension } \\
\text { movement }\end{array}$ & $\begin{array}{l}\text { Scoliosis } \\
\text { movement }\end{array}$ & $\begin{array}{l}\text { Torsion } \\
\text { movement }\end{array}$ \\
\hline State 1 & $10.01 \pm 0.39$ & $9.05 \pm 0.25$ & $7.42 \pm 1.06$ & $6.92 \pm 1.15$ \\
\hline State 2 & $7.21 \pm 0.17$ & $5.07 \pm 0.02$ & $5.12 \pm 0.74$ & $4.58 \pm 0.01$ \\
\hline$t$-value & 4.349 & 8.002 & 4.473 & 4.800 \\
\hline$P$-value & 0.022 & 0.004 & 0.021 & 0.017 \\
\hline
\end{tabular}

Comparison of the range of activity in each direction of movement between state 1 and state 2 in group $D$ In group $D$, the range of activity in each direction of movement in state 2 was lower than that in state 1 , and the differences were statistically significant (all $P$-values $<0.05)$ (Table 4).

Table 4 Comparison of the range of movement of each specimen in group $D$ in each direction of movement in state 1 and state $2 \mathbb{V}^{\circ} \nabla^{\top} \mathrm{X} \pm \mathrm{s} \rrbracket$

\begin{tabular}{|lllll|}
\hline State & $\begin{array}{l}\text { Forward flexion } \\
\text { motion }\end{array}$ & $\begin{array}{l}\text { Extension } \\
\text { movement }\end{array}$ & $\begin{array}{l}\text { Scoliosis } \\
\text { movement }\end{array}$ & $\begin{array}{l}\text { Torsion } \\
\text { movement }\end{array}$ \\
\hline State 1 & $9.20 \pm 1.37$ & $7.38 \pm 0.88$ & $6.89 \pm 1.22$ & $6.00 \pm 0.52$ \\
\hline State 2 & $6.06 \pm 0.16$ & $3.99 \pm 0.02$ & $3.85 \pm 0.08$ & $3.47 \pm 0.10$ \\
\hline$t$-value & 5.041 & 4.146 & 12.323 & 10.583 \\
\hline$P$-value & 0.015 & 0.025 & 0.001 & 0.002 \\
\hline
\end{tabular}

Comparison of the range of movement in each direction of movement in state 2 between group $A$ and group $B$ and group $C$ and group $D$

The range of movement in each movement direction of each group state 2 is group $B$, group $A$, group $D$, and group $C$ from small to large. Comparing group $A$ and group $B$ under each state 2 , group $B$ is more stable than group $A$, and the difference is statistically significant (all $P$-values $<0.05$ ) (Table 5); group $C$ and group $D$ are compared under each state 2 , group $D$ is more stable than group $C$, and the differences were statistically significant (all $P$-values $<0.05$ ) $($ Table 6 ). 
Table 5 Comparison of the range of movement in each movement direction under each specimen state 2 of group $A$ and group $B\left({ }^{\circ} \otimes ' X \pm s \rrbracket\right.$

\begin{tabular}{|lllll|}
\hline State & $\begin{array}{l}\text { State 2 forward flexion } \\
\text { movement }\end{array}$ & $\begin{array}{l}\text { State 2 extension } \\
\text { movement }\end{array}$ & $\begin{array}{l}\text { State 2 scoliosis } \\
\text { movement }\end{array}$ & $\begin{array}{l}\text { State 2 torsion } \\
\text { movement }\end{array}$ \\
\hline $\begin{array}{l}\text { group } \\
\text { moup }\end{array}$ & $4.78 \pm 0.07$ & $2.91 \pm 0.16$ & $2.66 \pm 0.09$ & $2.23 \pm 0.05$ \\
\hline $\begin{array}{l}\text { group } \\
\text { B }\end{array}$ & $3.51 \pm 0.29$ & $1.74 \pm 0.04$ & $1.53 \pm 0.31$ & $1.23 \pm 0.08$ \\
\hline$t$-value & 7.406 & 5.582 & 6.532 & 9.400 \\
\hline$P$-value & 0.001 & 0.001 & 0.001 & 0.001 \\
\hline
\end{tabular}

Table 6 Comparison of the range of movement in each movement direction under each specimen state 2 of group $C$ and group $D\left({ }^{\circ} \otimes ’ X \pm s \rrbracket\right.$

\begin{tabular}{|lllll|}
\hline State & $\begin{array}{l}\text { State 2 forward flexion } \\
\text { movement }\end{array}$ & $\begin{array}{l}\text { State 2 extension } \\
\text { movement }\end{array}$ & $\begin{array}{l}\text { State 2 scoliosis } \\
\text { movement }\end{array}$ & $\begin{array}{l}\text { State 2 torsion } \\
\text { movement }\end{array}$ \\
\hline $\begin{array}{l}\text { group } \\
\text { moup }\end{array}$ & $7.21 \pm 0.17$ & $5.07 \pm 0.02$ & $5.12 \pm 0.74$ & $4.58 \pm 0.01$ \\
\hline $\begin{array}{l}\text { group } \\
\text { m }\end{array}$ & $6.06 \pm 0.16$ & $3.99 \pm 0.02$ & $3.85 \pm 0.08$ & $3.47 \pm 0.10$ \\
\hline$t$-value & 2.577 & 9.713 & 2.533 & 4.173 \\
\hline$P$-value & 0.042 & 0.001 & 0.043 & 0.006 \\
\hline
\end{tabular}

\section{Discussion}

Tuberculosis is the second most deadly infectious disease in the world. The World Health Organization (WHO) announced in the "Global Tuberculosis Report 2015"[7]: In 2014, there were approximately 9.6 million new tuberculosis patients worldwide, resulting in approximately 1.5 million People died. Spinal tuberculosis is a common type of extrapulmonary tuberculosis, accounting for about $50 \%$ of bone and joint tuberculosis ${ }^{[8]}$, of which lumbar tuberculosis ranks first with the highest incidence. At present, the treatment of lumbar spine tuberculosis is mostly combined with surgical treatment on the basis of conventional chemotherapy. TThe purpose of the treatment of lumbar tuberculosis surgery is to remove the lesions, release the spinal nerves, correct kyphotic deformities, rebuild the stability of the spine and protecting normal tissues and blood supply. Wang et al ${ }^{[9]}$ used traditional pedicle screw single-segment fixation to treat 34 patients with single-space lumbar tuberculosis infection. All patients are satisfied with the bone graft fusion rate and the degree of kyphosis correction, but the remaining height of the vertebral body is required to be between $1 / 3$ and $2 / 3$ to ensure that the diseased vertebral body meets the 
requirements for implantating pedicle screwand and can perform Supporting effect, thus limiting the clinical application of this surgical method. Because spinal tuberculosis often destroys the anterior and middle column structure of the vertebral body, it is often difficult for residual diseased vertebrae to use the three-column fixation effect of conventional pedicle screws for reliable fixation. At the same time, for more and more elderly spinal tuberculosis patients with osteoporosis, pedicle screws are difficult to provide effective resistance to pullout and torsion. Therefore, the current clinical spinal tuberculosis surgery mostly uses multi-segment fixation that fixes one or more motion units on the upper and lower vertebrae ${ }^{[10]}$. However, multi-segment fixation will obviously limit the normal range of motion of the spine, and the adjacent segments will degenerate the intervertebral discs of the adjacent segments due to increased stress, resulting in the so-called adjacent segment disease after spinal fixation and fusion [11]. Moreover, the more fixed segments, the greater the stress on the internal fixation, which can easily cause the internal fixation to loosen and break, leading to failure of the operation. In addition, multi-segment fixation also needs to expose more paravertebral tissues, which increases the operation time, intraoperative bleeding, and the number of fluoroscopy, which is not conducive to postoperative recovery. In order to preserve the normal motor unit of the spine to the greatest extent and increase the holding force of the screw, scholars at home and abroad have conducted a lot of research. Santoni et al ${ }^{[2]}$ first reported a new method in 2009, namely CBT screw fixation technology. This technique inserts the screw passes through the pedicle sagittal plane from the dorsal to the ventral side, and the axial position from the median to the lateral.The contact area of the inner wall of the posterior part, the outer wall of the anterior part of the pedicle and the anterior wall of the vertebral body) can increase the holding force by changing the direction of the nail channel in the cortical bone of the pedicle. CBT placement has the following advantages: (1) The insertion point is closer to the spinous process than traditional pedicle screws, so the incision required for exposure is smaller, and the damage to soft tissues and muscle dissection and traction operations is also less, which can reduce Bleeding during and after surgery improves the satisfaction of postoperative rehabilitation [12]; (2) The direction of nail placement is insidedown-out-up, so the adjacent intervertebral joints are less infringed, and iatrogenic vertebral facet joint intrusion is reduced. Reduce the incidence of adjacent segmental disease [13]; (3) The direction of screw placement is that the distal end of the screw is inclined to the cephalic and lateral sides, and the upward screw passage in the sagittal plane is away from the spinal cord, nerve roots, and dural sac to avoid injury Risk; at the same time, it is closer to the midline of the nail entry point, which avoids damage to the medial nerve branch ${ }^{[14,15]}$; (4) The cortical bone part of the pedicle complex can be used to the greatest extent to provide a higher holding force , Anti-axial pullout and anti-torsion ability, thereby reducing the risk of screw loosening and screw withdrawal after surgery, and can be applied to patients with osteopenia and osteoporosis; At the same time, CBT screws still have some shortcomings in clinical application: (1) CBT screws fix the middle and posterior columns of the spine, and cannot achieve the strength of three-column fixation. Therefore, it is difficult for patients with severe vertebral damage and kyphosis Fixation and correction of kyphotic deformity; (2) The fatigue resistance of CBT screws is lower than that of traditional pedicle screws, and the special entry point and trajectory of CBT screws destroy the integrity of the isthmus and pedicle of the vertebral body. The patient did not undergo intervertebral 
fusion, and the loosening rate of CBT screws was higher than that of traditional pedicle screws ${ }^{[16,17]}$. (3) If the diameter of the screw is too large, the pedicle fracture will cause the screw to penetrate the cortical bone and easily damage the upper nerve root, and the lower nerve root will be damaged if the head angle of the screw is not enough ${ }^{[18]}$.

This test is based on the specimen materials for in vitro biomechanics experiments reported by Smith et al ${ }^{[19]}$, Wilke ${ }^{[20]}$ believes that the pig spine can produce biomechanical properties comparable to human spine in in vitro biomechanical experiments The pig lumbar spine specimens (T12-L5) were used to simulate the human lumbar spine for the experiment.

At present, the Panjabi method ${ }^{[21]}$ is mostly used for biomechanical evaluation. The Gurr method ${ }^{[3]}$ was used to establish the L2-L3 anterior and middle column destruction model to evaluate the effect of different fixation methods on the mechanical reconstruction of the spinal tuberculosis model.

It can be seen from the results of this experiment that the 4 kinds of fixation methods simulated L2-L3 vertebral tuberculosis model after fusion and internal fixation have a smaller range of motion in all directions than the complete spine model. Simultaneously simulate the 4 groups of fixation schemes of L2-3 vertebral tuberculosis model after bone grafting and fusion fixation. The range of motion in the four directions of motion, from small to large, is group $B$, group $A$, group $D$, and group $C$.. The experimental results show that the four posterior internal fixation schemes can provide stronger biomechanical strength in the same state of the same model in application, and can be used in patients with spinal tuberculosis to recover to the spinal column before being eroded by tuberculosis. Stable and functional. Compared with the four fixation methods, the short segment (sick vertebra CBT screw) fixation is stronger than the short segment (sick vertebra pedicle screw) fixation; the stability of the diseased intervertebral CBT screw fixation is stronger than that of the diseased intervertebral pedicle screw.

It should be noted that this experiment is a mechanical test of In vitro specimen spine specimens, which can only reflect the immediate stability after fixation, and cannot reflect the physiological dynamic stability during the postoperative fusion process. In addition, it is difficult to fully reflect the actual situation in the body due to the removal of the auxiliary structures such as muscles, ligaments and other soft tissues. The number of specimens in this experiment is small and there are certain limitations. The conclusion still needs a large number of samples for further verification.

\section{Conclusion}

CBT screw disease intervertebral fixation can provide reliable biomechanical strength and screw holding force, and at the same time make up for the limitation of the previous diseased intervertebral pedicle screw placement, and increase the indications of diseased intervertebral fixation for the treatment of lumbar tuberculosis. Provide experimental basis for the feasibility of CBT screw fixation in the treatment of lumbar tuberculosis 


\section{Abbreviations}

CBT : ortical bone trajectory screw ; MTS: motion simulation test system

\section{Declarations}

\section{Acknowledgements}

We would like to acknowledge and thank the Biomechanics Laboratory of Tianjin Medical University

\section{Authors' contributions}

CWZ, JF were responsible for experimental design, data collection and analysis and manuscript writing, SYS, DXH were involved in manuscript writing and data collection and analysis, CWZ, JF, SPH, JPH participated in laboratory experiments and prepared supplementary materials, PZ, RX analyzed Data, explained the results and prepared the numbers. All authors have read and approved the final manuscript.

\section{Funding}

2018 Zhejiang Province Medicine and Health Science and Technology Project(2018KY606)

Hangzhou Agricultural and Social Development Research Initiative Design Project (20180417A04)

\section{Availability of data and materials}

The datasets used and/or analyzed during the current study are available from the corresponding author upon reasonable request

\section{Ethics approval and consent to participate}

Informed consent was obtained from the families of all subjects. This study was approved by the ethics committee of the Hangzhou Chest Hospital, Zhejiang University School of Medicine

\section{Consent for publication}

Participants' consent to publish was granted.

\section{Competing interests}

The authors declare that they have no competing interests

\section{Author details}

Department of Orthopaedic, Affiliated Hangzhou Chest Hospital, Zhejiang University School of Medicine区 No. 208هHuancheng East Road 『Hangzhou 310005®Zhejiang Province『China. 


\section{References}

[1] García-Rodríguez JF, Álvarez-Díaz H, Lorenzo-García MV, Mariño-Callejo A, Fernández-Rial Á, SesmaSánchez P. Extrapulmonary tuberculosis: epidemiology and risk factors. Enferm Infecc Microbiol Clin, 2011, 29:502-509.

[2] Agrawal V, Patgaonkar PR, Nagariya SP. Tuberculosis of spine. J Craniovertebr Junction Spine, 2010, 1: 74-85.

[3] Jin D, Qu D, Chen J, et al. One-stage anterior interbody autografting and instrumentation in primary surgical management of thoracolumbar spinal tuberculosis. Eur Spine J, 2004, 13(2):114-21. doi: $10.1007 / \mathrm{s} 00586-003-0661-5$

[4] Jiang T, Zhao J, He M, et al. Outcomes and Treatment of Lumbosacral Spinal Tuberculosis: A Retrospective Study of 53 Patients. PLoS One, 2015, 10(6):e0130185. doi: 10.1371/journal.pone.0130185 [5] Santoni BG, Hynes RA, McGilvray KC, et al. Cortical bone trajectory for lumbar pedicle screws. Spine J, 2009, 9(5):366-73. doi: 10.1016/j.spinee.2008.07.008

[6] Gurr KR, McAfee PC, Shih CM. Biomechanical analysis of anterior and posterior instrumentation systems after corpectomy. A calf-spine model. J Bone Joint Surg Am, 1988, 70(8):1182-91

[7] Zumla A, George A, Sharma V, et al. The WHO 2014 global tuberculosis report-further to go. Lancet Glob Health, 2015, 3: E10-E12.

[8] Pigrau-Serrallach C, Rodríguez-Pardo D. Bone and joint tuberculosis. Eur Spine J, 2013, 22: 556-566.

[9] Wang Z, Yuan H, Geng G, et al. Posterior mono-segmental fixation, combined with anterior debridement and strut graft, for treatment of the mono-segmental lumbar spine tuberculosis. Int Orthop, 2012, 36(2):325-9. doi: 10.1007/s00264-011-1475-4

[10] Rajasekaran S, Kanna RM, Shetty AP. History of spine surgery for tuberculous spondylodiscitis. Unfallchirurg, 2015, 118 Suppl 1:19-27. doi: 10.1007/s00113-015-0093-9

[11] Virk SS, Niedermeier S, Yu E, et al. Adjacent segment disease. Orthopedics, 2014, 37(8):547-55. doi: 10.3928/01477447-20140728-08

[12] Phan K, Hogan J, Maharaj M, et al. Cortical Bone Trajectory for Lumbar Pedicle Screw Placement: A Review of Published Reports. Orthop Surg, 2015, 7(3):213-21. doi: 10.1111/os.12185

[13] Matsukawa K, Kato T, Yato Y, et al. Incidence and Risk Factors of Adjacent Cranial Facet Joint Violation Following Pedicle Screw Insertion Using Cortical Bone Trajectory Technique. Spine (Phila Pa 1976), 2016, 41(14):E851-6. doi: 10.1097/BRS.0000000000001459 
[14] Chen YR, Deb S, Pham L, et al. Minimally Invasive Lumbar Pedicle Screw Fixation Using Cortical Bone Trajectory - A Prospective Cohort Study on Postoperative Pain Outcomes. Cureus, 2016, 8(7):e714. doi: $10.7759 /$ cureus.71

[15]Hung CW, Wu MF, Hong RT, et al. Comparison of multifidus muscle atrophy after posterior lumbar interbody fusion with conventional and cortical bone trajectory. Clin Neurol Neurosurg, 2016, 145:41-5. doi: 10.1016/j.clineuro.2016.03.00

[16] Akpolat YT, İnceoğlu S, Kinne N, et al. Fatigue Performance of Cortical Bone Trajectory Screw Compared With Standard Trajectory Pedicle Screw. Spine (Phila Pa 1976), 2016, 41(6):E335-41. doi: $10.1097 / B R S .0000000000001233$

[17] Glennie RA, Dea N, Kwon BK, et al. Early clinical results with cortically based pedicle screw trajectory for fusion of the degenerative lumbar spine. J Clin Neurosci, 2015, 22(6):972-5. doi:

10.1016/j.jocn.2015.01.010

[18] Ninomiya K, Iwatsuki K, Ohnishi YI, et al. Significance of the Pars Interarticularis in the Cortical Bone Trajectory Screw Technique: An In Vivo Insertional Torque Study. Asian Spine J, 2016, 10(5):901-906. doi: 10.4184/asj.2016.10.5.901

[19] Smith TJ. In vitro spinal biomechanics. Experimental methods and apparatus. Spine (Phila Pa 1976), 1991, 16(10):1204-10. doi: 10.1097/00007632-199110000-00013

[20] Wilke HJ, Krischak S, Claes L. Biomechanical comparison of calf and human spines. J Orthop Res, 1996, 14(3):500-3. doi: 10.1002/jor.1100140321

[21] Panjabi MM. Biomechanical evaluation of spinal fixation devices: I. A conceptual framework. Spine (Phila Pa 1976), 1988, 13(10):1129-34. doi: 10.1097/00007632-198810000-00013

\section{Figures}




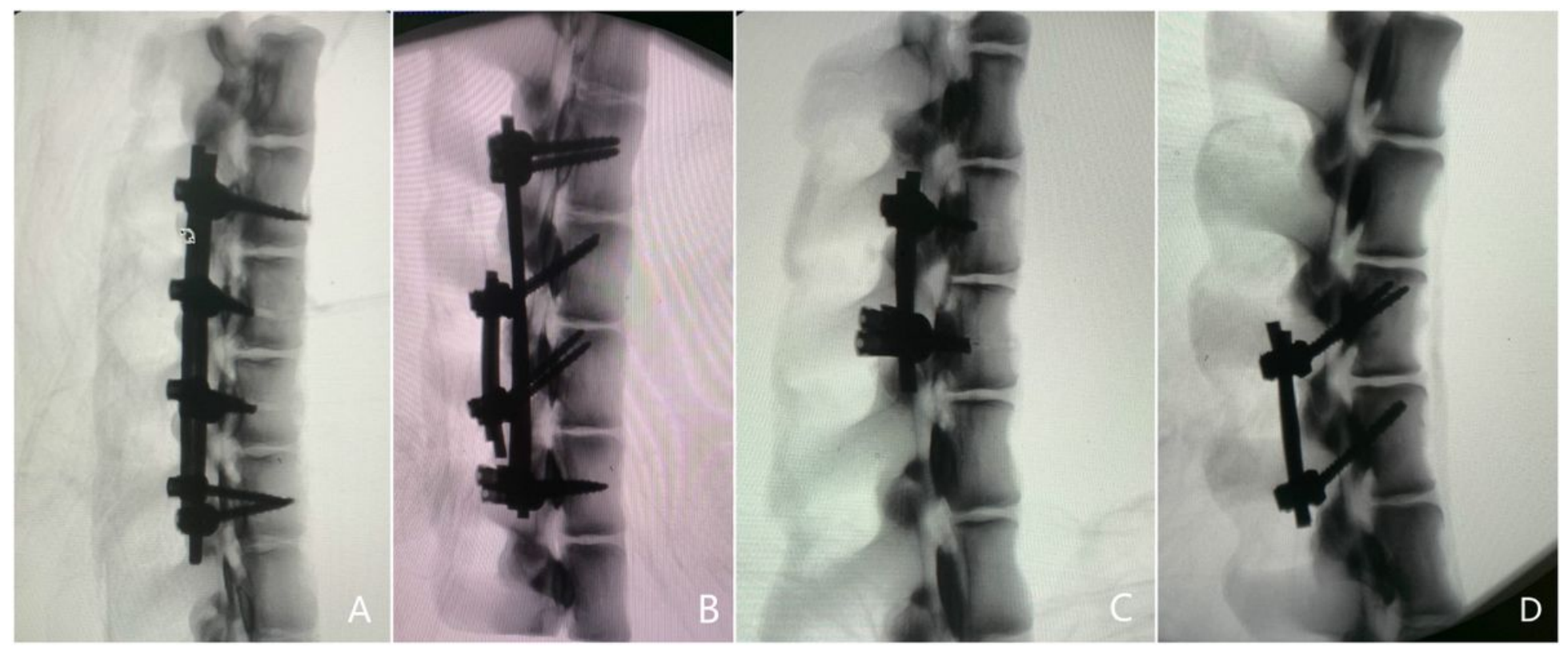

\section{Figure 1}

fixation mode of models in each group (A) Group A using short segment fixation (lesion vertebrae used pedicle screw), that is, L1 and L4 used long screw, L2 and L3 using short screw. (B) Group B used short segment fixation (lesion vertebrae used CBT screw), that is, L1 and L4 used long screw, L2 and L3 used CBT screw. (C) Group C used diseased intervertebral pedicle screw, that is, L2 and L3 used short screw. (D) Group D. the diseased vertebrae were fixed with CBT screws, that is, L2 and L3 were fixed with CBT

\section{screws}

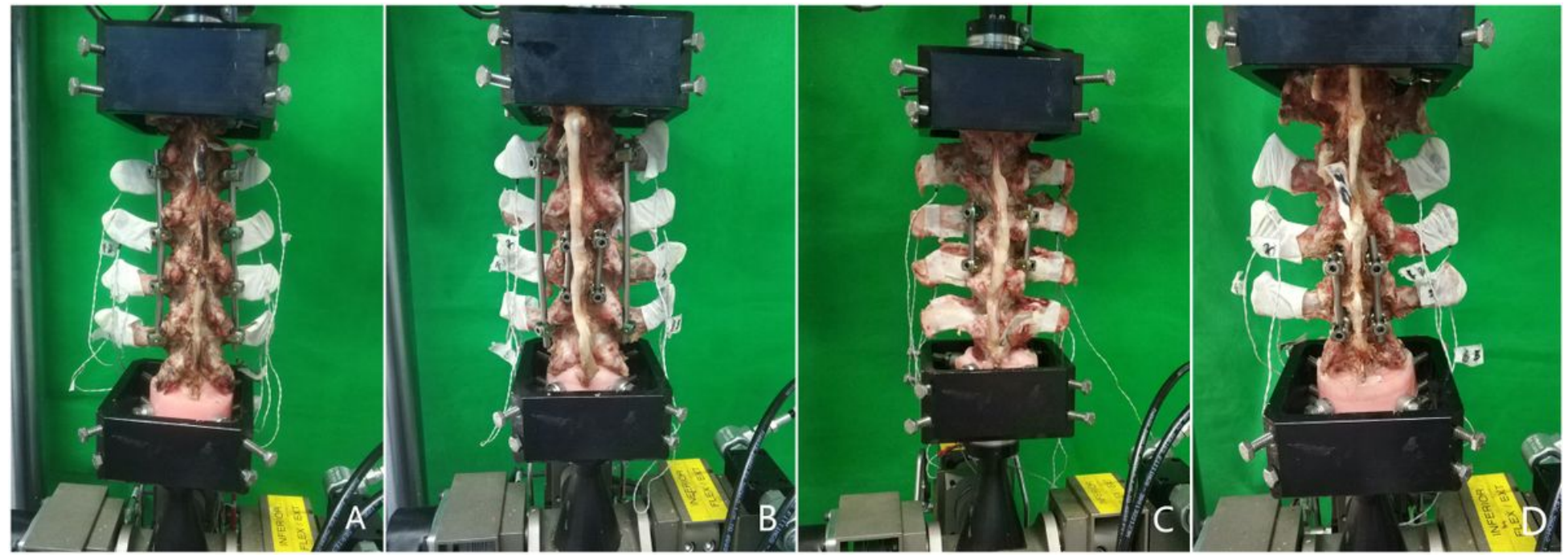

Figure 2

The appearance of each group of models after modeling (state 2) (A) shows the status of bone graft fusion and internal fixation after modeling L2-L3 spinal tuberculosis in group A. (B) shows the status of bone graft fusion and internal fixation after modeling L2-L3 spinal tuberculosis in group B. (C) shows the status of bone graft fusion and internal fixation after modeling L2-L3 spinal tuberculosis in group C. (D) 
shows the status of bone graft fusion and internal fixation after modeling L2-L3 spinal tuberculosis in group D.

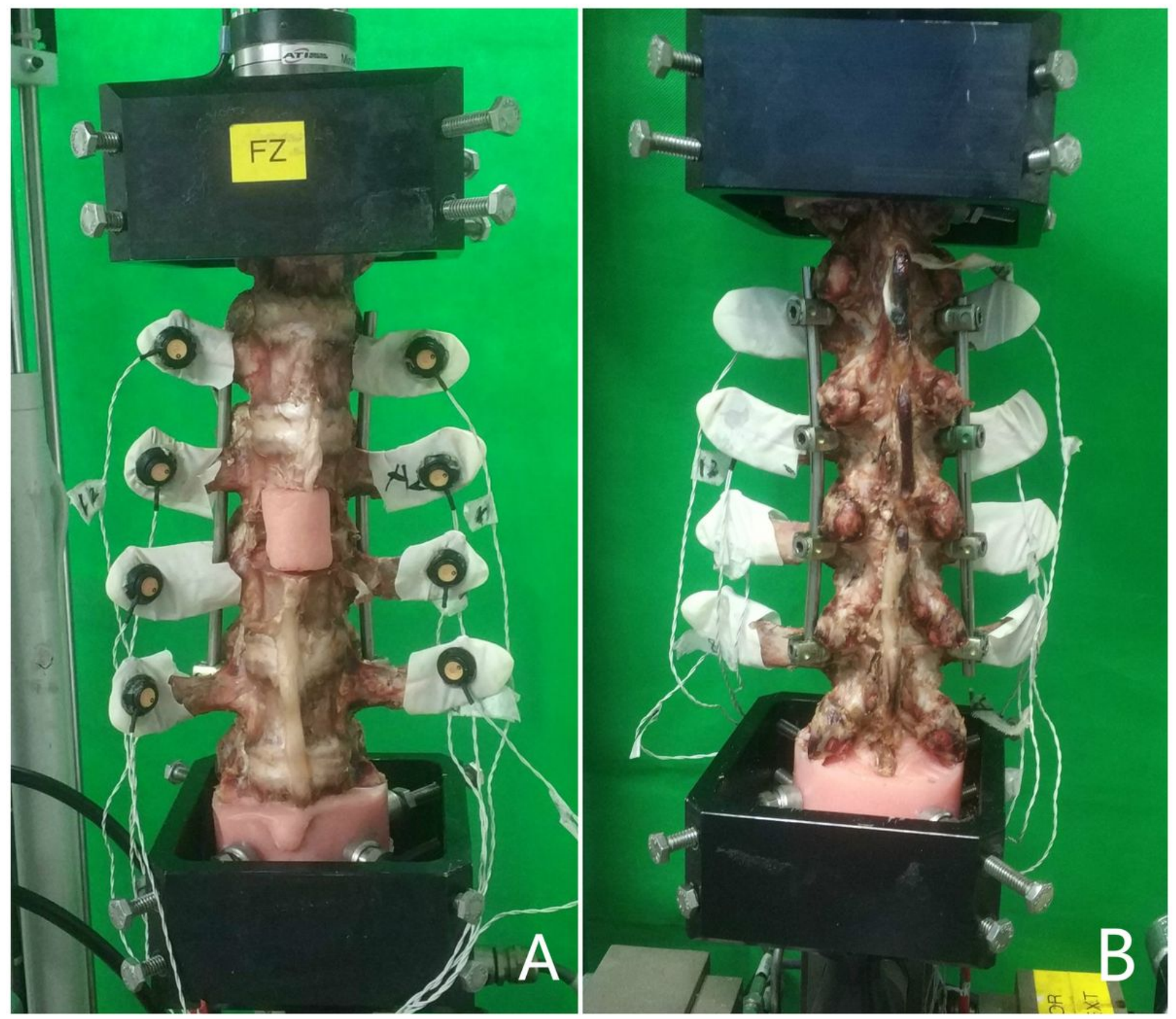

\section{Figure 3}

Fixing situation of the specimen after being put on the machine (A) The front view of the machine fixed on the A group state 2. (B) The back view of the machine fixed on the A group state 2 


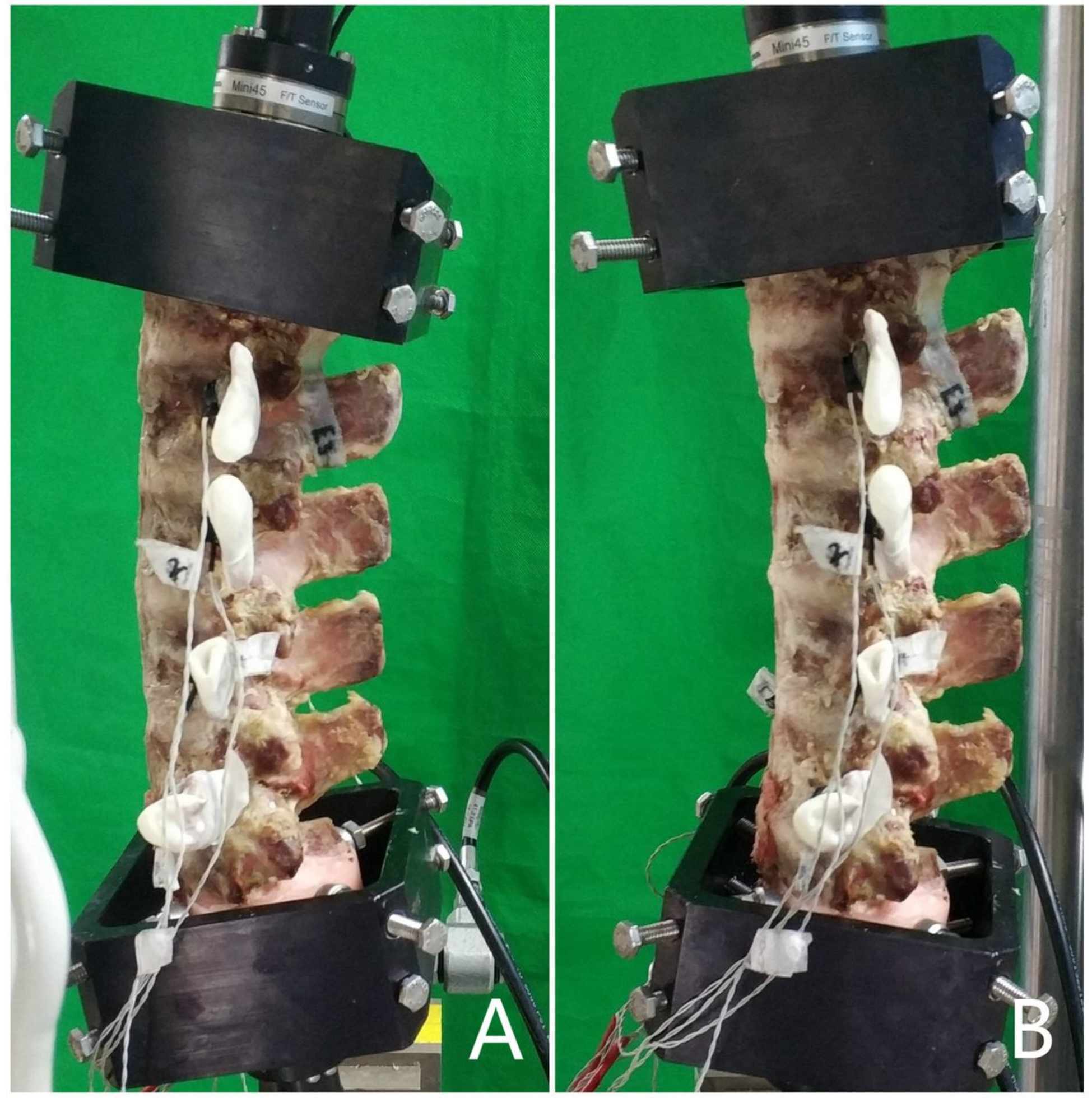

\section{Figure 4}

The movement of the sample on the machine under the corresponding torque. (A) The specimen in state 1 using $2 \mathrm{~N} \cdot \mathrm{m}$ pure torque to perform forward flexion movement. (B) The specimen in state 1 using $2.5 \mathrm{~N} \cdot \mathrm{m}$ pure torque to perform backward extension. 